\title{
Meme kanserli bir hastada 18-Floro-de-oksi-Glukoz pozitron emisyon tomografisinde multiple kemik metastazları: Olgu sunumu ve literatürün gözden geçirilmesi
}

\author{
Multiple bone metastases detected on 2-[18F]-fluoro-2-deoxy-d-glucose positron emission \\ tomography in a breast cancer patient: Case report and literature review
}

\author{
Zeki Dostbil ${ }^{1}$, Buğra Kaya ${ }^{2}$, Oktay Sarı ${ }^{3}$, Erhan Varoğlu' ${ }^{2}$, Murat İsmailoğlu²
}

\section{ÖZET}

Kemik sintigrafisi, meme kanserli hastaların iskelet sistemi metastazlarının değerlendirilmesinde halen yaygın olarak kullanılmaktadır. 18F-FDG-PET/BT, malign hücrelerde artmış glukoz metabolizmasının görüntülenmesi prensibine dayanarak metastazları tespit etmede son yıllarda yaygın kullanım alanı kazanmış diğer bir görüntüleme yöntemidir. Genel olarak, meme kanserinin kemik metastazlarının tespitinde bu iki yöntem benzer sonuçlar vermektedir. Meme kanserli bu olguda 99mTc-MDP kemik sintigrafisi kemik metastazı yönünden normal bulgular göstermesine karşın 18F-FDG-PET/BT, kontrastlı BT ve MR'da iskelet sisteminde birçok odakta kemik metastazları tespit edilmiştir.

Anahtar kelimeler: 18F-florodeoksiglikoz, kemik metastazı, kemik sintigrafisi, pozitron emisyon tomografisi

\section{Giriş}

Meme kanseri tüm dünyadaki kadınlarda en sık görülen kanser türüdür. Kemik, meme kanserinin en sık metastaz yaptığı bölgelerdendir. ${ }^{1}$ Kemik metastazları ileri evre meme ve prostat kanserlerinde \%70'e; akciğer, kolon, mide, mesane, uterus, rektum, tiroid ve böbrek kanserlerinde ise \%15-30'a varan oranlarda görülmektedir. ${ }^{2,3}$ Kanser hastalarında kemik metastazlarının tespiti en doğru tedavinin belirlenmesinde önemli bir faktördür. Kemik metastazları osteoblastik, osteolitik veya mikst karakterde olabilir. Meme kanserli hastalarda çoğunlukla osteolitik kemik metastazları görülürken en az \%15-20'si osteoblastik karakterde olmaktadır. ${ }^{4}$

Görüntüleme yöntemlerinin amaçlarından biri de kemik metastazlarının erken tespitidir. Röntgenografi, bilgisayarlı tomografi (BT) ve manyetik re-

\begin{abstract}
Bone scintigraphy has been widely used to assess skeletal metastasis in patients with breast cancer. 18F-FDG$\mathrm{PET} / \mathrm{CT}$ is another imaging modality that has gained previously wide use to determine metastasis based on increased glucose metabolism in malignant cells. Generally, these two modalities give similar results in evaluation of bone metastasis of breast cancer. In this breast cancer case, 99mTc-MDP bone scintigraphy showed normal findings in regards to skeletal metastasis while 18FFDG-PET/CT, contrast-enhanced CT and MRI revealed multiple metastatic focuses. J Clin Exp Invest 2012; 3 (3): 426-429
\end{abstract}

Key words: 18F-fluorodeoxyglucose, bone metastasis, bone scintigraphy, positron emission tomography

zonans (MR) görüntüleme kemik metastazlarının görüntülenmesinde kullanılan anatomik görüntüleme teknikleridir. ${ }^{5}$ BT, röntgenografiye göre kemik yapıları değerlendirmede daha üstün bir yöntemdir. Bu nedenle kemik metastazlarının değerlendirilmesinde BT tercih edilir. Diğer yandan, MR görüntüleme diğer modalitelere göre kemik iliğini daha iyi görüntüler. Kemikteki tümörün yumuşak dokuya olan invazyonları, röntgenografi ve BT ile karşılaştırıldığında MR ile daha iyi değerlendirilebilmektedir. ${ }^{6}$

Şimdiye kadar kemik sintigrafisi kemik metastazlarının tespitinde en sık kullanılan görüntüleme yöntemlerinden biri olmuştur. Çünkü yüksek sensitivitesi, tüm vücut tarama imkanı ve kolay ulaşılabilir olması gibi avantajları vardır. ${ }^{7}$ 99mTc-metilen difosfonat (99mTc-MDP) kemik sintigrafisinde en yaygın kullanılan ajandır. 99mTc-MDP tutulumu kemikteki osteoblastik aktiviteyi yansıttığından; kemik sintig-

\footnotetext{
${ }^{1}$ Dicle Üniversitesi Tıp Fakültesi Nükleer Tıp Anabilim Dalı, Diyarbakır, Türkiye

${ }^{2}$ Konya Üniversitesi Meram Tıp Fakültesi Nükleer Tıp Anabilim Dalı, Konya, Türkiye

${ }^{3}$ Selçuk Üniversitesi Selçuklu Tıp Fakültesi Nükleer Tıp Anabilim Dalı, Konya, Türkiye
}

Correspondence: Zeki Dostbil,

Dicle Üniversitesi Tıp Fakültesi, Nükleer Tıp Anabilim Dalı, Diyarbakır, Türkiye Email: zekidostbil@yahoo.com

Received: 10.03.2012, Accepted: 29.04.2012

Copyright (C) JCEI / Journal of Clinical and Experimental Investigations 2012, All rights reserved 
rafisi meme, prostat ve akciğer kanseri gibi daha çok osteoblastik tipte metastaz yapan tümörlerin kemik metastazlarının tespitinde etkilidir. ${ }^{7}$ Son yıllarda kanser hastalarında tanı, evreleme ve takipte yaygın kullanım alanı kazanmış bir görüntüleme yöntemi olan 18F-florodeoksiglikoz pozitron emisyon tomografisinin (18FDG-PET) kemik metastazlarının tespitinde faydalı olduğu gösterilmiştir. ${ }^{7} \mathrm{Bu}$ yöntem vücudun glukoz metabolizmasını görüntüler. Kemik sintigrafisi litik kemik metastazlarının tespitinde duyarlı değildir. 18F-FDG-PET ise litik kemik metastazlarının tespitinde yüksek duyarlılığa sahiptir. ${ }^{7} \mathrm{Ge}-$ nel olarak kemik sintigrafisi ve 18F-FDG-PET yöntemleri kemik metastazlarının tespitinde birbirleriyle benzer sonuçlar vermektedir. ${ }^{2}$ Ancak, sunduğumuz bu olgu ile iki modalite arasında uyumsuz sonuçlar da olabileceğine işaret ettik.

\section{OLGU}

Olgumuz 1 yıl önce sağ memede infiltratif duktal karsinom tanısı konmuş ve bu nedenle Konya Üniversitesi Meram Tıp Fakültesi Genel Cerrahi Kliniğinde sağ mastektomi yapılmış olan 39 yaşında kadın hastaydı. Hastanın genel durumu iyi ve aktif şikayeti yoktu. Hasta daha önceden kemoterapi ya da radyoterapi almamıştı. Üç hafta önce yapılan 99mTc-MDP sintigrafisinde metastatik bulgulara rastlanmadı (Şekil 1). Hastaya evreleme amacıyla Nükleer Tıp Kliniğimizde IV kontrast madde verilmeden yapılan 18FDG-PET/BT görüntülemede çeşitli organ ve dokularda multiple metastazların yanı sıra iskelet sisteminde de multiple kemik metastazları ile uyumlu artmış 18FDG tutulumları vardı: servikal 2 ve 5 . , torakal 9 . ve 10 ., lomber 3. vertebralarda, sakrum, pelvis, sağ femur proksimali, sol humerus başı ve şaftında multiple odaklarda (Şekil 2). Tanımlanan lezyonlar BT'de sklerotik karakterdeydi. Kemik sintigrafisi ve 18FDG-PET çalışması yapıldığı tarihlere göre 1 hafta içinde ölçülen serum total ALP değerleri normal sınırlardaydı. Bir ay içerisinde yapılan BT ve MR incelemelerinde; servikal MR'da C7'de, Torakal BT ve MR'da T3 ve T11'de, Lomber BT ve MR'da L3'de metastatik lezyonlar tarif ediliyordu. Sakral MR normal rapor edilmişti.

PET/BT görüntüleme; hastaların çekimden önce en az 6 saat aç kalmaları sağlandı. $370 \mathrm{Me}-$ gabecquerel (10 mCi) 18FDG enjeksiyonundan yaklaşık $60 \mathrm{dk}$ sonra, hastalar entegre PET/BT cihazı (Siemens, Biograph True Point 6 PET/CT, Germany) kullanılarak görüntülendi. BT görüntüleme intravenöz kontrast madde kullanılmadan gerçekleştirildi. PET'de atenuasyon düzeltme BT verilerine dayanılarak yapıldı. Kemik sintigrafisi, hastaya 740 MBq (20 mCi) 99mTc-MDP enjeksiyonundan yaklaşık 2-4 saat sonra gama kamera cihazı (Siemens, E-Cam gamma camera, Germany) kullanılarak tüm vücut tarama şeklinde yapıldı.

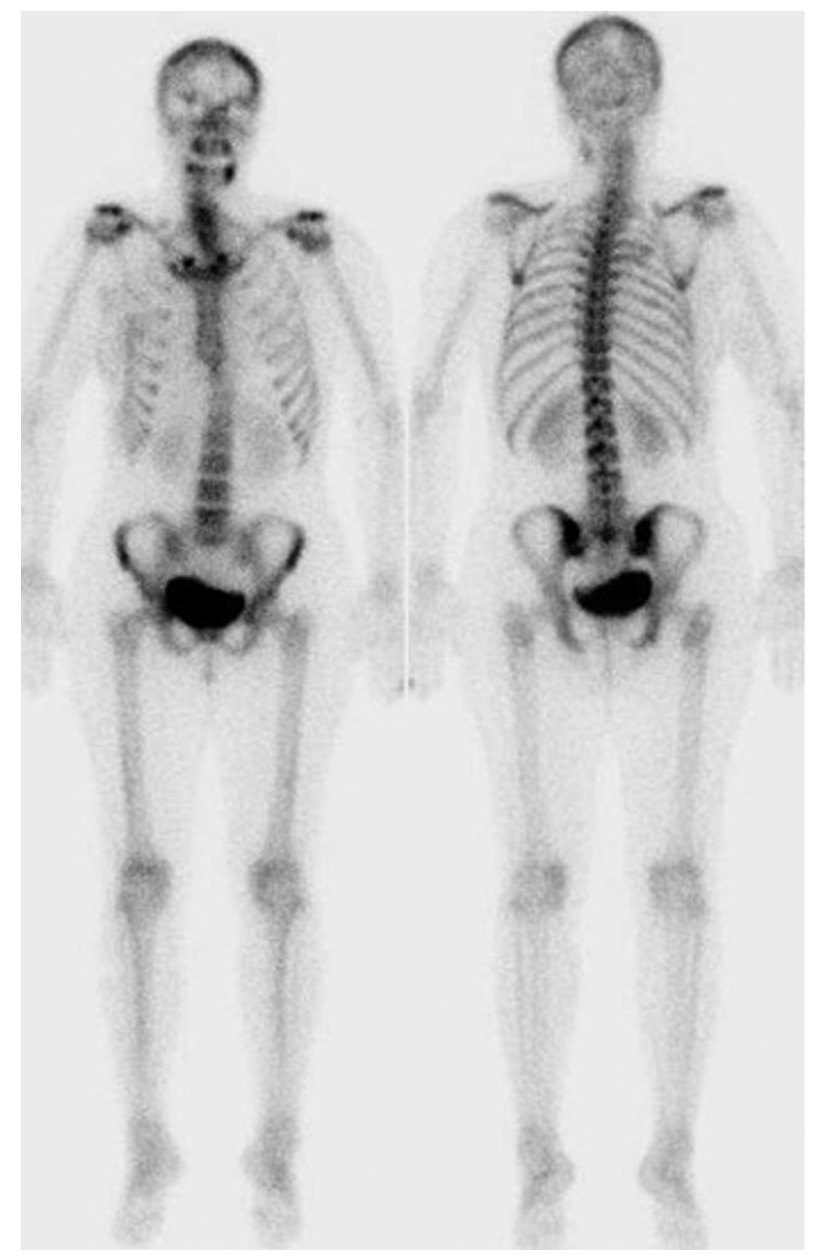

Şekil 1. Meme kanserli 39 yaşındaki kadın hastanın 99mTc-MDP sintigrafi görüntüsü. Kemik metastazı düşündürecek herhangi bir bulgu görülmüyor. 


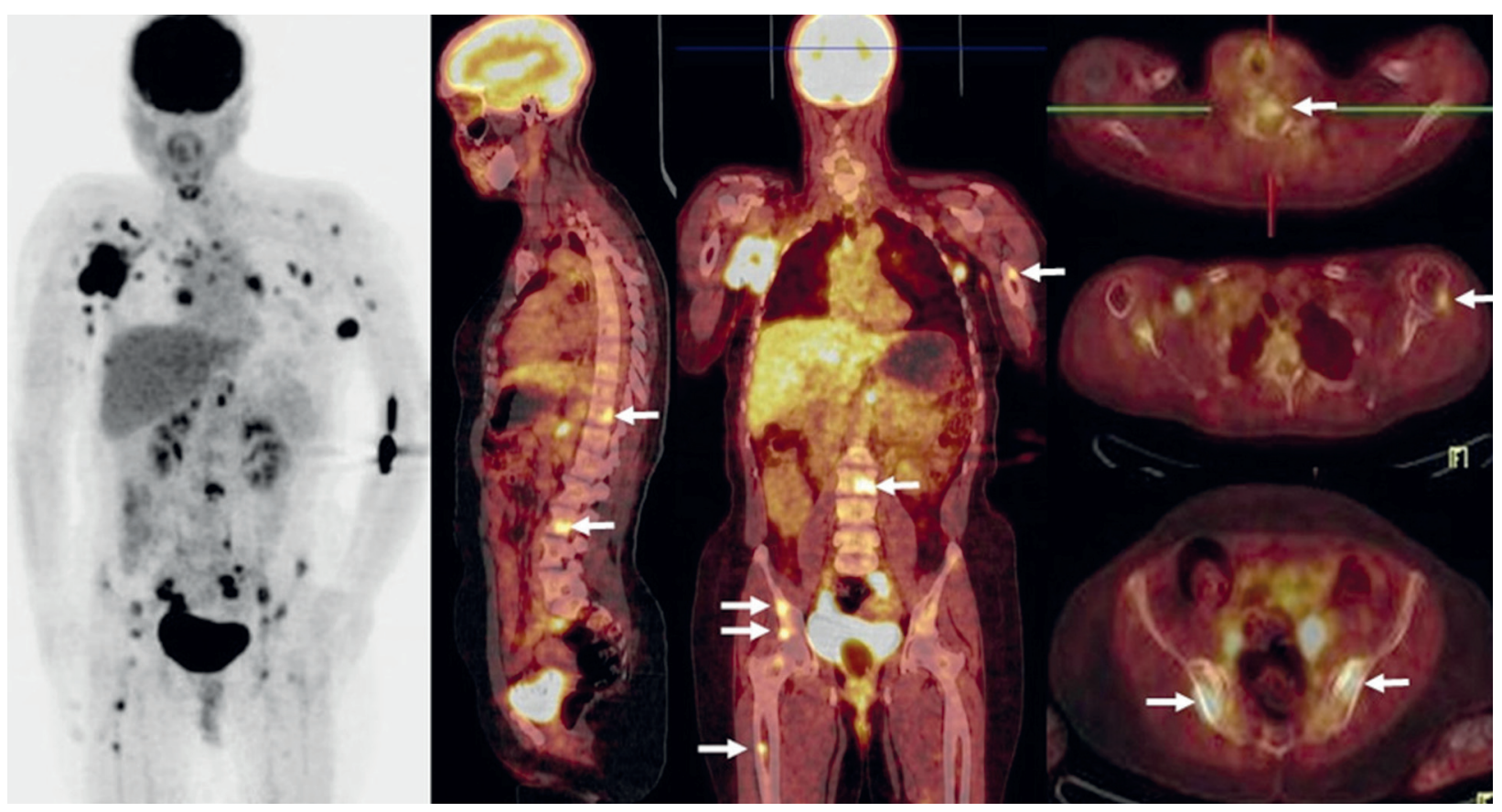

Şekil 2. Solda aynı hastanın 18FDG-PET ve sağda PET/BT füzyon görüntüleri. Yumuşak dokuda ve iskelet sisteminde çok sayıda metastatik odak izleniyor.

\section{TARTIŞMA}

Tümörlerdeki yüksek kan akımı ve bazı adeziv moleküllerin varlığı, transformin büyüme faktörü beta, IGF-I, IGF-II, fibroblast büyüme faktörü, trombosit kökenli büyüme faktörü, kemik morfojenik proteinleri ve kalsiyum hep birlikte kemiği uygun metastaz bölgesi haline getirmektedir. ${ }^{4}$ Normal kemik çevriminde yapım ile yıkım arasında bir denge bulunmaktadır: önce osteoklastlar kemiği rezorbe eder sonra da osteoblastlar aynı yerde yeni kemik oluşturur. ${ }^{2}$ Osteoblastik metastazlarda metastaz bölgesinde osteoblastik aktivitede artış görülür. Osteolitik metastazlarda kemik yıkımı tümör hücrelerinden ziyade osteoklastlar tarafından gerçekleştirilmektedir. ${ }^{8}$

Metastatik kemik lezyonlarının tespiti tedavi planlamasında önemlidir. Çünkü tümörün kemiğe metastaz yaptığı vakalarda genellikle tam kür sağlanamaz: meme kanserli hastaların sadece \%20'si kemik metastazı tespit edildikten 5 yıl sonra hala sağ kalmaktadır. ${ }^{9}$ Genel olarak kemik sintigrafisi kemik metastazlarını göstermede duyarlı olmakla birlikte özgüllüğü oldukça düşüktür. Çünkü enfeksiyon, travma, artropati gibi patolojiler de radyofarmasötik tutulumunu arttırmaktadır. ${ }^{10}$ Yapılan çalışmalarda, kemik metastaz tespitinde kemiğe spesifik ALP'ın ümit verici sonuçları olmakla birlikte serum total ALP'ın düşük tanısal değeri olduğu bildirilmiştir. ${ }^{10}$ Bizim vakamızda 18FDG-PET/BT, kontrastlı BT ve MR görüntülemede çok odakta kemik metastazları tanımlanırken serumda ölçülen total ALP değerleri normal sınırlar içinde bulunmuştu.

18FDG-PET özellikle sklerotik kemik metastazlarını kaçırabilir. ${ }^{11}$ Sklerotik kemik metastazları kemik sintigrafisi ile daha kolay tespit edilebilir. ${ }^{11}$ Ancak, bizim olgumuzda metastatik kemik sintigrafisinde lezyon görülmemesine rağmen 18FDG-PET/ BT'de servikal 2. ve 5. , torakal 9. ve 10., lomber 3. vertebralarda; sakrum, pelvis, sağ femur proksimali, sol humerus başı ve şaftında multiple sklerotik kemik metastazları tanımlanmıştı (Şekil 1,2). Bizim bu vakamız kemik sintigrafisinin tespit edemediği bazı sklerotik metastazları 18FDG-PET/BT'nin tespit edebileceğini göstermiştir. Artık rutinde yapılan PET görüntülerinin BT görüntüleri ile birlikte değerlendirilmesi kemik metastazlarının tespitinde başarıyı arttırmaktadır. ${ }^{12,13}$ BT görüntülemenin kemik metastaz araştırmasında tarama testi olarak kullanımı tavsiye edilmemektedir. ${ }^{14}$ Ancak, kemik sintigrafisi ve $P E T$ gibi diğer görüntüleme yöntemlerindeki anormal görünümlerin teyiti amacıyla ikincil görüntüleme tekniği olarak kullanımı önerilmektedir. ${ }^{14}$ Groves et al. kemik sintigrafisi ile 16-kesit tüm vücut BT görüntülemeyi karşılaştırmak için 43 hastada yaptıkları bir çalışmada, kemik sintigrafisi 43 hastanın 14'ünde, BT ise 13 'ünde kemik metastazı tespit etmiştir. ${ }^{15} \mathrm{Ay}$ rıca hastaya vereceği radyasyon dozu da gözönüne alındığında tüm vücut BT taramanın kemik metastazlarını tespit etmede rutinde kullanılmasına gerek olmadığı sonucuna varılmıştır. ${ }^{15}$ 
Yapılan torakal ve lomber kontrastlı BT ve MR'da, torakal 3. ve 11. vertebralarda metastaz tanımlanırken, PET/BT'de torakal 9. ve 10. vertebralarda tarif edilen lezyonlar tespit edilemedi. Kontrastlı BT'nin 18FDG-PET görüntülerinin daha doğru yorumlanmasına katkısı bulunduğu bildirilmiştir. ${ }^{16}$ Bu nedenle kontrastsız yapılan 18FDG-PET/BT'de tespit edilemeyen torakal 3 . ve 11. vertebralardaki metastatik lezyonlar kontrastlı BT'de tespit edilebildi. Torakal 9. ve 10. vertebralarda 18FDG-PET/ BT'de metastaz olarak tanımlanan lezyonlar muhtemelen osteodejeneratif değişikliklere bağlı benign lezyonlardır. İnflamasyon, 18FDG tutulumunu arttıran sebeplerden biridir. ${ }^{10}$ Lomber 3 . vertebradaki metastatik lezyon her üç modalitede de raporlanmıştı. Ancak, kemik sintigrafisi iskelet sisteminin diğer bölgelerinde olduğu gibi metastaz bulgusu göstermemişti. 18FDG-PET/BT'de sakral bölgede birkaç adet kemik metastazı tespit edilirken sakral MR normaldi. Liu et al. yaptıkları bir meta-analizde kemik metastazlarını tespit etmede 18FDG-PET/ BT, MR görüntüleme ve kemik sintigrafisinin sensitivitesini sırasıyla \%95, \%83.8 ve $\% 71.5$; spesifiteyi ise sırasıyla $\% 94.6, \% 96.3$ ve $\% 91$ olarak bildirmişlerdir. ${ }^{5}$ MR'ın malign kemik lezyonlarını tespit etmede bazı sınırlılıkları vardır. Kortikal kemik harabiyetini göstermede 18FDG-PET/BT'ye göre daha az duyarlı olduğu bildirilmektedir. ${ }^{5}$

Türkiye'de son yıllarda iskelet sistemi görüntülemesinde 18F-NaF PET kullanımı gündeme gelmeye başlamıştır. Florid iyonunun kemik tutulumu teknesyumla işaretli polifosfonatların iki katıdır. ${ }^{10}$ Even-Sapir et al. 18F-NaF PET'in litik ve sklerotik malign kemik lezyonlarını tespit etmede oldukça sensitif ve spesifik bir yöntem olduğunu bildirmişlerdir. ${ }^{17}$ Yapılan bir çalışmada 18F-NaF PET'in osteolitik ve osteoblastik kemik metastazlarının tespitinde kemik sintigrafisinden daha sensitif olduğu bildirilmiştir (\%91.6; \%41.7, sırasıyla). ${ }^{18}$

Sonuç olarak, kanserli hastalarda kemik sintigrafisi ile 18FDG-PET/BT görüntülerinin birlikte değerlendirilmesiyle kemik metastazlarının tespit edilmesinde daha doğru sonuçlara ulaşılabilir.

\section{KAYNAKLAR}

1. Ohta M, Tokuda $Y$, Suzuki $Y$, et al. Whole body PET for the evaluation of bony metastases in patients with breast cancer: comparison with 99Tcm-MDP bone scintigraphy. Nucl Med Commun 2001;22(8):875-9.

2. Chen YW, Huang MY, Hsieh JS, Hou MF, Chou SH, Lin $\mathrm{CL}$. Discordant findings of skeletal metastasis between tc 99M MDP bone scans and F18 FDG PET/CT imaging for advanced breast and lung cancers--two case reports and literature review. Kaohsiung J Med Sci 2007;23(12):63946.
3. Coleman RE, Rubens RD. The clinical course of bone metastases from breast cancer. Br J Cancer 1987;55(1):61-6.

4. Roodman GD. Mechanisms of bone metastasis. N Engl J Med 2004;350(16):1655-64.

5. Liu T, Xu JY, Xu W, Bai YR, Yan WL, Yang HL. Fluorine-18 deoxyglucose positron emission tomography, magnetic resonance imaging and bone scintigraphy for the diagnosis of bone metastases in patients with lung cancer: which one is the best?-a meta-analysis. Clin Oncol (R Coll Radiol) 2011;23(5):350-8.

6. Schmidt GP, Reiser MF, Baur-Melnyk A. Whole-body imaging of the musculoskeletal system: the value of MR imaging. Skeletal Radiol 2007;36(12):1109-19.

7. Ozülker T, Küçüköz AU, Ozülker F, Ozpaçacı T. Comparison of (18)F-FDG-PET/CT with (99m)Tc-MDP bone scintigraphy for the detection of bone metastases in cancer patients. Nucl Med Commun 2010;31(6):597-603.

8. Taube T, Elomaa I, Blomqvist C, Beneton MN, Kanis JA. Histomorphometric evidence for osteoclast-mediated bone resorption in metastatic breast cancer. Bone 1994;15(2):161-6.

9. Coleman RE. Metastatic bone disease: clinical features, pathophysiology and treatment strategies. Cancer Treat Rev 2001;27(3):165-76.

10. Min JW, Um SW, Yim JJ, et al. The role of whole-body FDG PET/CT, Tc 99m MDP bone scintigraphy, and serum alkaline phosphatase in detecting bone metastasis in patients with newly diagnosed lung cancer. J Korean Med Sci 2009;24(2):275-80.

11. Gallowitsch HJ, Kresnik E, Gasser J, et al. F-18 fluorodeoxyglucose positron-emission tomography in the diagnosis of tumor recurrence and metastases in the follow-up of patients with breast carcinoma: a comparison to conventional imaging. Invest Radiol 2003;38(5):250-6.

12. Nakamoto Y, Cohade C, Tatsumi M, Hammoud D, Wahl $\mathrm{RL}$. CT appearance of bone metastases detected with FDG PET as part of the same PET/CT examination. Radiology 2005;237(2):627-34.

13. Kao CH, Hsieh JF, Tsai SC, Ho YJ, Yen RF. Comparison and discrepancy of 18F-2-deoxyglucose positron emission tomography and tc-99m MDP bone scan to detect bone metastases. Anticancer Res 2000;20(3B):2189-92.

14. Tombal B, Lecouvet F. Modern detection of prostate cancer's bone metastasis: Is the bone scan era over? Adv Urol 2012;2012(7):893-9.

15. Groves AM, Beadsmoore CJ, Cheow HK, et al. Can 16-detector multislice CT exclude skeletal lesions during tumour staging? Implications for the cancer patient. Eur Radiol 2006;16(5):1066-73.

16. Kitajima K, Suzuki K, Nakamoto Y, et al. Low-dose nonenhanced CT versus full-dose contrast-enhanced CT in integrated PET/CT studies for the diagnosis of uterine cancer recurrence. Eur $\mathrm{J}$ Nucl Med Mol Imaging 2010;37(8):1490-8.

17. Even-Sapir E, Metser U, Mishani E, Lievshitz G, Lerman $\mathrm{H}$, Leibovitch I. The detection of bone metastases in patients with highrisk prostate cancer: 99mTc-MDP planar bone scintigraphy, singleand multi-field-of-view SPECT, 18F-Fluoride PET, and 18F-Fluoride PET/CT. J Nucl Med 2006;47(2):287-97.

18. Schirrmeister H, Glatting G, Hetzel J, et al. Prospective evaluation of the clinical value of planar bone scans, SPECT, and (18)F-labeled NaF PET in newly diagnosed lung cancer. J Nucl Med 2001;42(12):1800-4. 